Bull. Chem. Soc. Ethiop. 2016, 30(2), 283-288.

Printed in Ethiopia

DOI: http://dx.doi.org/10.4314/bcse.v30i2.12

ISSN 1011-3924

(C) 2016 Chemical Society of Ethiopia

\title{
SYNTHESIS OF HYDROXYMETHYLFURFURAL FROM SUCROSE USING BRÖNSTED-LEWIS ACIDIC IONIC LIQUID
}

\author{
Lin Yao, Shiwei Liu*, Lu Li, Shitao Yu*, Fusheng Liu and Zhanqian Song \\ College of Chemical Engineering, Qingdao University of Science and Technology, Qingdao \\ 266042, China
}

(Received March 11, 2014; revised May 20, 2016)

\begin{abstract}
The synthesis of 5-hydroxymethylfurfural (HMF) from sucrose was investigated in the presence of the Brönsted-Lewis acidic ionic liquids (ILs). It was concluded that IL 1-(3-sulfonic acid)-propyl-3methylimidazole chlorochrominate $\left[\mathrm{HO}_{3} \mathrm{~S}-\left(\mathrm{CH}_{2}\right)_{3}-\mathrm{mim}\right] \mathrm{Cl}-\mathrm{CrCl}_{3}\left(\right.$ molar fraction of $\left.\mathrm{CrCl}_{3} x=0.55\right)$ had a good catalytic performance with $78.8 \%$ yield of HMF. The acid type of IL played a significant role in the reaction. Lewis acid site acted more effectively than its Brönsted counterpart and a synergetic effect of Brönsted and Lewis acid sites enhanced the IL catalytic performance. The reusability of IL was good.
\end{abstract}

KEY WORDS: Acidic ionic liquid, Sucrose, 5-Hydroxymethylfurfural, Catalysis

\section{INTRODUCTION}

5-Hydroxymethylfurfural (HMF) is one key furan derivative readily accessible from renewable resources like carbohydrates, in particular through acid-catalyzed reaction of biomass sugar such as fructose, sucrose and glucose. HMF is a particularly suitable starting material for the preparation of further furan monomers required for the preparation of non-petroleum-derived polymeric materials, such as polyesters, polyamides and polyurethanes [1, 2]. Usually the traditional inorganic acids, such as $\mathrm{H}_{2} \mathrm{SO}_{4}$ [3], were used as catalysts in these reaction. The drawbacks of these processes include low selectivity of the desired HMF, serious corrosion of equipments, complicated separation procedures, environmental problems, and not recyclable of catalysts. Solid catalysts, such as the aluminophosphates [4], transition metal phosphate [5] and sulfonic acid functionalized mesoporous silica [6], were also reported as catalysts in these reactions. They also have shortcomings, such as restricted accessibility to the matrix bound catalytic sites, high molecular weight/active site ratios, and rapid deactivation from coking. Therefore, it is necessary to explore a new approach for the synthesis of HMF from sucrose. HMF is actually formed from the reaction of sucrose through a series of intermediates [7]. The process is composed of several elementary reactions, such as protonation, dehydration, and deprotonation (Scheme 1). Generally, Brönsted acid is active to protonation and dehydration, and Lewis acid facilitates the deprotonation [8].

As a kind of environmental-friendly catalysts, Brönsted or Lewis acidic ionic liquids (ILs) get attentions of researchers [9], and many organic reactions, such as transesterification [10], alkylation [11], polymerization [12] and carbonylation [13] were reported with excellent selectivity, and the used ILs were of outstanding recyclability. Studies involving the utilization of ILs as reaction media or as catalysts for the reaction of biomass sugar to HMF have also been

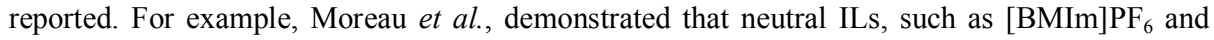
$[\mathrm{BMIm}] \mathrm{BF}_{4}$, acted as a suitable reaction medium for the dehydration of fructose to HMF in the presence of the acidic catalyst Amberlyst-15 [14]. The Brönsted acidic IL, 1-H-3-methyl imidazolium chloride was also used as both solvent and catalyst for the reactions of fructose and sucrose to produce HMF [15]. Recently, metal chlorides in the neutral IL [EMIm]Cl was found to be an effective catalyst for converting biomass sugar to HMF. The above results suggested

*Corresponding author. E-mail: liushiweiqust@126.com 
that ILs as solvents or catalysts played a positive role in the development of an effective process for the reaction of sugars to HMF [8]. In our laboratory, some Brönsted-Lewis acidic ILs were synthesized, characterized and used in the polymerization $[16,17]$. The results indicated that the Brönsted-Lewis acidic ILs were both Brönsted and Lewis acidic and had the better catalytic performance for the polymerization than the traditional catalysts. Due to the presence of Brönsted and Lewis acid sites, these ILs can selectively catalyze different reaction mechanisms to enhance the reaction conversion and selectivity. As an extension of our ongoing studies of these acidic ILs, we reported herein their applications as catalysts for the reaction of sucrose to produce HMF, together with an effort to characterize ILs using UV-visible spectroscopy. The characterization results revealed that the type of IL acidity played a significant role in the efficiency of the reaction.

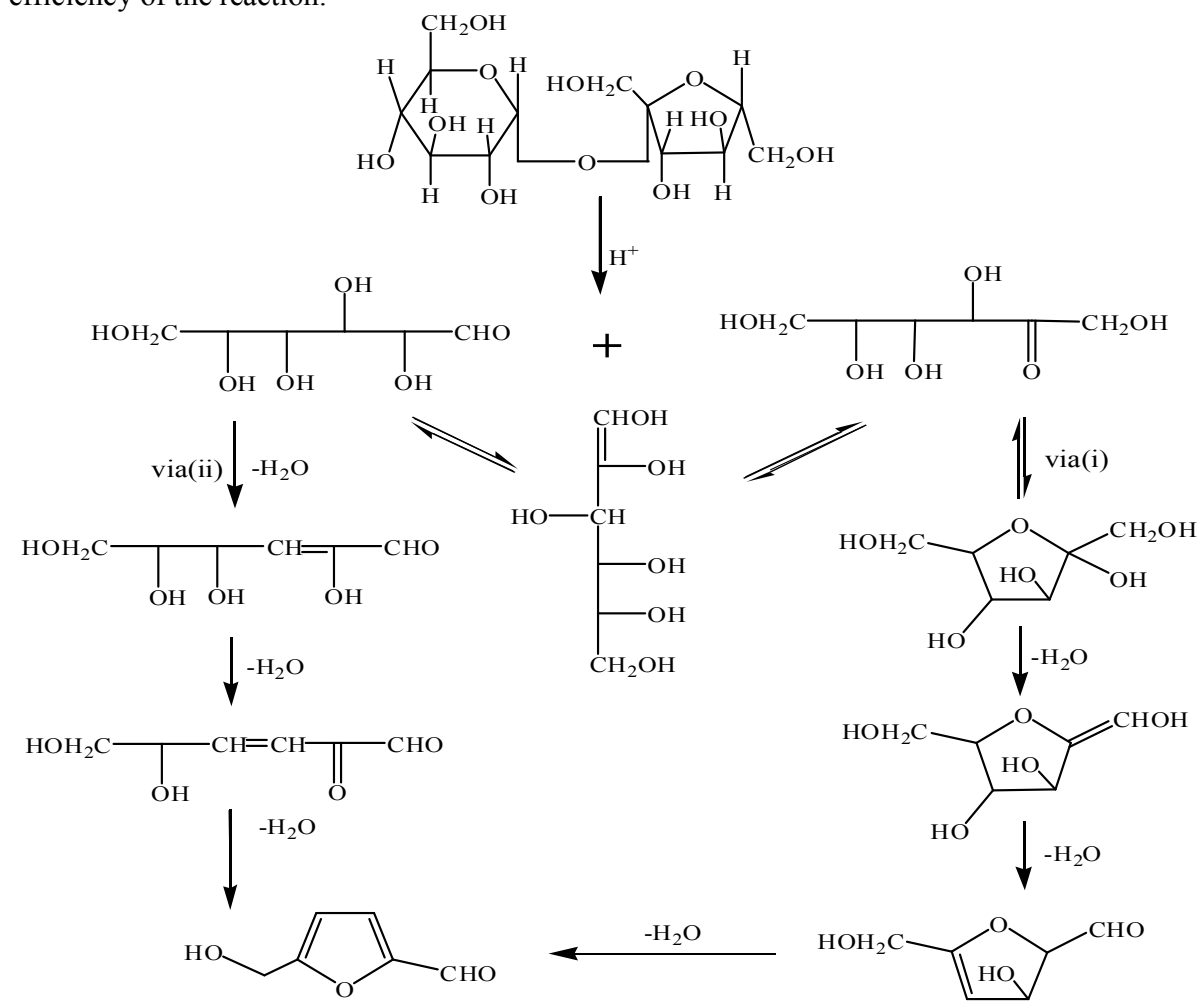

Scheme 1. Reaction of sucrose to HMF.

\section{EXPERIMENTAL}

\section{Materials and apparatus}

Sucrose (99.8 wt\%, Sigma Aldrich), 1-methylimidazole (99.8 wt\%, Sigma Aldrich), 1,3propane sultone (1,2-oxathiolane-2,2-dioxide, $99.7 \mathrm{wt} \%$, Albright and Wilson), and other chemicals (analytic purity) were commercially available and used without further purification.

IR spectra were recorded by a Nicolet 510P FT-IR spectrometer in the range of 4500-400 $\mathrm{cm}^{-1}$. NMR spectra were taken by a Bruker AV500 Fourier-Transform spectrometer with 
reference to $\mathrm{SiMe}_{4}$, using solvent $\mathrm{D}_{2} \mathrm{O}$ containing $5 \mathrm{wt} \%$ of the sample. Quantitative analysis of the product sample was recorded by HP-LC, which was a Shimadzu LC-6A pump and a refractive index RID-6A detector. The used column was a BIORAD HPX-87H $(300 \mathrm{~mm} \times 7.8$ $\mathrm{mm})$. Deionized water was the eluent $(0.6 \mathrm{~mL} / \mathrm{min})$, and sorbose was the internal standard.

\section{Preparation of ILs}

Using the procedure in the literature [16] 1,3-propane sultone was reacted with $\mathrm{N}$ methylimidazole to give 3-(methylimidazole-N-yl)-propane-1-sultonate as zwitterion. Then it was reacted with an equal mole of hydrochloric acid to give (3-sulfonic acid)-propylmethylimidazole chloride $\left[\mathrm{HO}_{3} \mathrm{~S}-\left(\mathrm{CH}_{2}\right)_{3}-\mathrm{mim}\right] \mathrm{Cl}$ as a white viscous liquid at room temperature. The Brönsted-Lewis acidic ILs were prepared by the reaction of $\left[\mathrm{HO}_{3} \mathrm{~S}-\left(\mathrm{CH}_{2}\right)_{3}\right.$-mim]Cl with metal chlorides, including $\mathrm{FeCl}_{3}, \mathrm{ZnCl}_{2}$ and $\mathrm{CrCl}_{3}$. The Lewis acidity of IL depended on the metal chloride mass. When the molar fraction of metal chloride was less than 0.5, IL only had Brönsted acidity and no Lewis acidity, and above this value, the obtained IL was BrönstedLewis acidic. The reaction formula for the synthesis of IL $\left[\mathrm{HO}_{3} \mathrm{~S}-\left(\mathrm{CH}_{2}\right)_{3}-\mathrm{mim}\right] \mathrm{Cl}-\mathrm{CrCl}_{3}(\mathrm{x}=$ 0.67 ) was showed in Scheme 2. The acidities of ILs were characterized and determined on the basis of the Hammett acidity function. As shown in the following equation, the Hammett acidity function can be expressed as:

$H_{0}=\mathrm{p} K(\mathrm{I})_{a q}+\log \left([\mathrm{I}] /[\mathrm{IH}]^{+}\right)$

where $\mathrm{p} K(\mathrm{I})_{a q}$ is the $\mathrm{p} K_{a}$ value of the indicator $p$-nitroaniline referred to as the aqueous solution, $[\mathrm{IH}]^{+}$and $[\mathrm{I}]$ are respectively the molar concentrations of the protonated and unprotonated forms of the indicator, which is usually determined by UV-visible spectroscopy [20]. $\left[\mathrm{HO}_{3} \mathrm{~S}-\left(\mathrm{CH}_{2}\right)_{3}-\right.$ $\operatorname{mim}] \mathrm{Cl}-\mathrm{CrCl}_{3}(\mathrm{x}=0.67)$ : IR $\left(\mathrm{KBr}\right.$ disc, $\mathrm{cm}^{-1)}: v 3380,2987,1627,1483,1147,1044,738,606$. ${ }^{1} \mathrm{H}$ NMR (500 MHz, $\left.\mathrm{D}_{2} \mathrm{O}, \mathrm{ppm}\right): \delta 1.95(\mathrm{t}, 2 \mathrm{H}), 2.83(\mathrm{t}, 2 \mathrm{H}), 3.15(\mathrm{~m}, 2 \mathrm{H}), 3.64(\mathrm{~s}, 3 \mathrm{H}), 6.86(\mathrm{t}$, $1 \mathrm{H}), 7.01(\mathrm{t}, 1 \mathrm{H}), 7.38(\mathrm{~s}, 1 \mathrm{H}) .{ }^{13} \mathrm{C}$ NMR $\left(255 \mathrm{MHz}, \mathrm{D}_{2} \mathrm{O}, \mathrm{ppm}\right): \delta 134.70,122.33,121.15$, $47.24,46.93,34.25,24.73$.

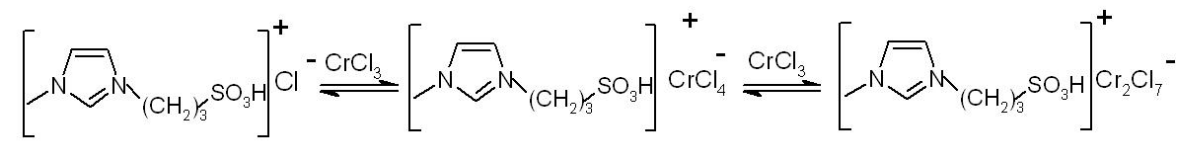

Scheme 2. Synthesis of IL $\left[\mathrm{HO}_{3} \mathrm{~S}-\left(\mathrm{CH}_{2}\right)_{3}-\mathrm{mim}\right] \mathrm{Cl}-\mathrm{CrCl}_{3}(x=0.67)$.

\section{Catalytic properties test}

In a typical experiment, $2.0 \mathrm{~g}$ sucrose, $20 \mathrm{~mL}$ dimethyl sulfoxide and $1.6 \mathrm{~g}$ IL were added into a $50 \mathrm{~mL}$ stainless steel autoclave and reacted for $30 \mathrm{~min}$ at $200{ }^{\circ} \mathrm{C}$. After the reaction, the reaction mixture was cooled, and the upper layer, containing the product, solvent dimethyl sulfoxide and unreacted reactant, was separated from the IL layer at the bottom of the flask simply by decantation. The IL layer was reused directly in the cycle experiments. All samples of the upper layer were analyzed by HP-LC. Analyses were performed using a Shimadzu LC-6A pump and a refractive index RID-6A detector. The used column was a BIORAD HPX-87H $(300 \mathrm{~mm} \times 7.8$ $\mathrm{mm})$. Deionized water was the eluent $(0.6 \mathrm{~mL} / \mathrm{min})$, and sorbose was the internal standard. HMF yield was directly given by the system of LC chemstation according to the area of each chromatograph peak. 


\section{RESULTS AND DISCUSSION}

\section{Effects of different catalysts on the reaction}

As can be seen from Table 1, compared with the traditional catalyst $\mathrm{H}_{2} \mathrm{SO}_{4}$ (30 wt\%), all Brönsted-Lewis acidic ILs exhibited better catalytic performance. Especially, IL $\left[\mathrm{HO}_{3} \mathrm{~S}-\left(\mathrm{CH}_{2}\right)_{3}\right.$ $\operatorname{mim}] \mathrm{Cl}-\mathrm{CrCl}_{3}(x=0.55)$ exhibited good catalytic property with more than $78 \%$ yield of the product HMF. When Lewis acidic IL $\left[\mathrm{C}_{4} \mathrm{mim}\right] \mathrm{Cl}-\mathrm{CrCl}_{2}(x=0.55)$ and Brönsted acidic IL $\left[\mathrm{HO}_{3} \mathrm{~S}-\left(\mathrm{CH}_{2}\right)_{3}-\mathrm{min}\right] \mathrm{Cl}$ were used as catalysts, the yields of $\mathrm{HMF}$ were only $37.1 \%$ and $48.7 \%$, respectively. When the fractions of metal chloride $(x)$ were less than 0.5 , the obtained ILs were only Brönsted acidic, and their Hammett acidity functions $\left(\mathrm{H}_{0}\right)$ were near to those of BrönstedLewis acidic ILs which the fractions of metal chloride $(x)$ were more than 0.5 , but the results of the reaction used them as catalysts were not satisfied. It was indicated that the type of acidity played a significant role in the efficiency of the reaction reaction. The good catalytic performance of Brönsted-Lewis acidic IL was due to its types of Brönsted and Lewis acidities and a synergetic effect. The Brönsted and Lewis acid sites can selectively catalyze the elementary reactions, such as protonation, dehydration, and deprotonation, on the reaction processes of the sucrose to HMF through a series of cyclic furan intermediates, and the synergetic effect of both acidic sites enhanced the catalytic performance of IL (Scheme 1.). The metal chlorides had a decisive influence on the catalytic performances of ILs, and IL $\left[\mathrm{HO}_{3} \mathrm{~S}\right.$ $\left.\left(\mathrm{CH}_{2}\right)_{3}-\mathrm{mim}\right] \mathrm{Cl}-\mathrm{CrCl}_{3}(x=0.55)$ showed the best catalytic performance. These results can be explained by the different role on the stability to the product $\mathrm{HMF}$, and $\mathrm{CrCl}_{3}$ plays a good role in stabilizing HMF, which can hinder the decomposition of HMF to form levulinic acid and formic acid. Among the chlorochrominate ILs, the HMF yield was increased with the molar fraction of $\mathrm{CrCl}_{3}(x)$. When $x$ value was 0.55 , the reaction of sucrose was effectively catalyzed. This can be explained by that, when the molar fraction of metal chloride $(x)$ was more than 0.5 , IL was Brönsted and Lewis acidic, and by increasing the $x$ value, the Lewis acidity was increased [18], which can increase the catalytic activity of IL. But further increased $x$ value, the result was not good. It was indicated that too high a Lewis acid strength was adjective for the reaction.

Table 1. Effects of catalysts on the reaction results ${ }^{\mathrm{a}}$.

\begin{tabular}{|c|c|c|c|c|}
\hline Entry & Catalyst & $\mathrm{H}_{0}$ & Conversion $/ \%$ & Yield $/ \%$ \\
\hline 1 & Blank & - & - & 0 \\
\hline 2 & {$\left[\mathrm{C}_{4} \mathrm{mim}\right] \mathrm{Cl}$} & - & 95.0 & 14.6 \\
\hline 3 & {$\left[\mathrm{C}_{4} \mathrm{mim}\right] \mathrm{Cl}-\mathrm{CrCl}_{3}(x=0.55)$} & - & 92.9 & 37.1 \\
\hline 4 & $30 \mathrm{wt} \% \mathrm{H}_{2} \mathrm{SO}_{4}$ & -1.53 & 96.5 & 46.6 \\
\hline 5 & {$\left[\mathrm{HO}_{3} \mathrm{~S}-\left(\mathrm{CH}_{2}\right)_{3}-\mathrm{mim}\right] \mathrm{Cl}$} & 2.91 & 92.6 & 48.7 \\
\hline 6 & {$\left[\mathrm{HO}_{3} \mathrm{~S}-\left(\mathrm{CH}_{2}\right)_{3}-\mathrm{mim}\right] \mathrm{Cl}-\mathrm{ZnCl}_{2}(x=0.33)$} & 3.21 & 95.8 & 70.2 \\
\hline 7 & {$\left[\mathrm{HO}_{3} \mathrm{~S}-\left(\mathrm{CH}_{2}\right)_{3}-\mathrm{mim}\right] \mathrm{Cl}-\mathrm{ZnCl}_{2}(x=0.55)$} & 2.81 & 96.0 & 77.3 \\
\hline 8 & {$\left[\mathrm{HO}_{3} \mathrm{~S}-\left(\mathrm{CH}_{2}\right)_{3}-\mathrm{mim}\right] \mathrm{Cl}-\mathrm{ZnCl}_{2}(x=0.60)$} & 2.62 & 94.9 & 73.6 \\
\hline 9 & {$\left[\mathrm{HO}_{3} \mathrm{~S}-\left(\mathrm{CH}_{2}\right)_{3}-\mathrm{mim}\right] \mathrm{Cl}-\mathrm{FeCl}_{3}(x=0.33)$} & 2.84 & 94.9 & 60.7 \\
\hline 10 & {$\left[\mathrm{HO}_{3} \mathrm{~S}-\left(\mathrm{CH}_{2}\right)_{3}-\mathrm{mim}\right] \mathrm{Cl}-\mathrm{FeCl}_{3}(x=0.55)$} & 2.70 & 95.1 & 65.9 \\
\hline 11 & {$\left[\mathrm{HO}_{3} \mathrm{~S}-\left(\mathrm{CH}_{2}\right)_{3}-\mathrm{mim}\right] \mathrm{Cl}-\mathrm{FeCl}_{3}(x=0.60)$} & 2.64 & 95.1 & 66.1 \\
\hline 12 & {$\left[\mathrm{HO}_{3} \mathrm{~S}-\left(\mathrm{CH}_{2}\right)_{3}-\mathrm{mim}\right] \mathrm{Cl}-\mathrm{CrCl}_{3}(x=0.33)$} & 2.75 & 96.4 & 74.8 \\
\hline 13 & {$\left[\mathrm{HO}_{3} \mathrm{~S}-\left(\mathrm{CH}_{2}\right)_{3}-\mathrm{mim}\right] \mathrm{Cl}-\mathrm{CrCl}_{3}(x=0.55)$} & 2.56 & 97.7 & 78.7 \\
\hline 14 & {$\left[\mathrm{HO}_{3} \mathrm{~S}-\left(\mathrm{CH}_{2}\right)_{3}-\mathrm{mim}\right] \mathrm{Cl}-\mathrm{CrCl}_{3}(x=0.60)$} & 2.46 & 95.7 & 76.7 \\
\hline
\end{tabular}




\section{Effects of reaction conditions on the reaction}

The effects of reaction conditions were showed in Table 2. The IL dosage was very important for the reaction. With increasing of IL $\left[\mathrm{HO}_{3} \mathrm{~S}-\left(\mathrm{CH}_{2}\right)_{3}\right.$-mim] Cl- $\mathrm{CrCl}_{3}(x=0.55)$ dosage from 1.6 $\mathrm{g}$ to $2.8 \mathrm{~g}$, the yield of HMF increased from $72.2 \%$ to $78.8 \%$. When increasing of solvent dimethyl sulfoxide dosage from $10 \mathrm{~mL}$ to $30 \mathrm{~mL}$, the yield of HMF increased from $45.3 \%$ to $77.9 \%$. This result was due to the difference in dissolubility of sucrose and HMF in the reaction mixture. The reaction temperature and time were also important for the reaction. At $180{ }^{\circ} \mathrm{C}$, the HMF yield was only $65.4 \%$. But when the temperature reached $200{ }^{\circ} \mathrm{C}$, the HMF yield was reached to $78.7 \%$. However, the yield of product was not increased further after that. This may be because too high reaction temperature facilitated the decomposition of the product HMF. With increasing reaction time from $10 \mathrm{~min}$ to $30 \mathrm{~min}$, the yield of product HMF increased from $65.7 \%$ to $77.8 \%$. However, the HMF yield decreased to $72.1 \%$ at $40 \mathrm{~min}$. It can be seen that both too high a reaction temperature and too long a reaction time were unfavorable to the yield of HMF.

Table 2. Effects of reaction conditions on the reaction results.

\begin{tabular}{|c|c|c|c|c|c|c|}
\hline Entry & $\mathrm{IL} / \mathrm{g}$ & Solvent $/ \mathrm{mL}$ & $\mathrm{T} /{ }^{\circ} \mathrm{C}$ & $\mathrm{t} / \mathrm{min}$ & Conversion $/ \%$ & Yield $/ \%$ \\
\hline 1 & 1.6 & 20 & 200 & 30 & 92.3 & 72.2 \\
\hline 2 & 2.0 & 20 & 200 & 30 & 97.7 & 78.7 \\
\hline 3 & 2.4 & 20 & 200 & 30 & 97.4 & 78.6 \\
\hline 4 & 2.8 & 20 & 200 & 30 & 98.8 & 78.8 \\
\hline 5 & 2.0 & 10 & 200 & 30 & 95.0 & 45.3 \\
\hline 6 & 2.0 & 30 & 200 & 30 & 93.2 & 77.9 \\
\hline 7 & 2.0 & 20 & 180 & 30 & 94.6 & 65.4 \\
\hline 8 & 2.0 & 20 & 220 & 30 & 99.0 & 77.8 \\
\hline 9 & 2.0 & 20 & 240 & 30 & 100 & 65.0 \\
\hline 10 & 2.0 & 20 & 220 & 10 & 91.6 & 65.7 \\
\hline 11 & 2.0 & 20 & 220 & 20 & 94.6 & 67.9 \\
\hline 12 & 2.0 & 20 & 220 & 40 & 100 & 72.1 \\
\hline
\end{tabular}

\section{Reusability of catalyst}

The reusability of $\left[\mathrm{HO}_{3} \mathrm{~S}-\left(\mathrm{CH}_{2}\right)_{3}-\mathrm{mim}\right] \mathrm{Cl}-\mathrm{CrCl}_{3}(x=0.55)$ was investigated, and the results were given in Table 3. The results showed that HMF yield was almost unchanged after $\left[\mathrm{HO}_{3} \mathrm{~S}-\right.$ $\left(\mathrm{CH}_{2}\right)_{3}$-mim]Cl-CrCl${ }_{3}(x=0.55)$ was used repeatedly five times. It was indicated that the Brönsted-Lewis acidic IL was of excellent reusability. The good reusability may be explained by the following two points. Firstly, in the structure of IL, the alkyl sulfonic acid group is covalently tethered in IL cation, and the anions $\left[\mathrm{CrCl}_{4}\right]^{-}$and $\left[\mathrm{Cr}_{2} \mathrm{Cl}_{7}\right]^{-}$of IL are inert and stable in water and Brönsted acid. Therefore the acidity of IL is not easily lost. Secondly, the use of $\mathrm{CrCl}_{3}$ increases the density of the IL, which gives an easier separation of IL from the reaction mixture, and then IL is not easily lost in the separation process. Therefore, its activity was stable.

Table 3. Reusability of the IL catalyst.

\begin{tabular}{|c|c|c|}
\hline Cycle & Conversion $/ \%$ & Yield $/ \%$ \\
\hline 1 & 97.7 & 78.7 \\
\hline 2 & 97.9 & 78.6 \\
\hline 3 & 96.8 & 78.2 \\
\hline 4 & 97.5 & 78.5 \\
\hline 5 & 97.8 & 78.4 \\
\hline
\end{tabular}




\section{CONCLUSION}

The synthesis of 5-hydroxymethylfurfural (HMF) from sucrose was investigated using the Brönsted-Lewis acidic ILs as catalysts. IL (3-sulfonic acid)-propyl-methylimidazole chloroimidazole $\left[\mathrm{HO}_{3} \mathrm{~S}-\left(\mathrm{CH}_{2}\right)_{3}-\mathrm{mim}\right] \mathrm{Cl}-\mathrm{CrCl}_{3}(x=0.55)$ had the good catalytic property and the yield of product was $78.7 \%$. The type of acidity of ILs played a significant role in the efficiency of the reaction. The Brönsted-Lewis acidic sites of IL could selectively catalyze the protonation, dehydration, and deprotonation dehydrogenation in the reaction, and a synergetic effect of Brönsted and Lewis acid sites enhanced the catalytic performance of the IL.

\section{ACKNOWLEDGMENTS}

This work was financially supported by the Natural Science Foundation of Shandong (ZR2010BQ018) and the Postdoctoral Science Foundation of Shandong (201003051). The authors are grateful for the financial support.

\section{REFERENCES}

1. Chermahini, A.N.; Shahangi, F.; Dabbagh, H.A.; Saraji, M. RSC Advances 2016, 6, 33804.

2. Corma, A.; Iborra, S.; Velty, A. Chem. Rev. 2003, 107, 2411.

3. Nikolla, E.; Roman-Leshkov, Y.; Moliner, M.; Davis, M.E. ACS Catalysis 2011, 1, 408.

4. Gemechu, D.; Wondimagenge, M.; Yonas, C.; Isabel D. Bull. Chem. Soc. Ethiop. 2014, 28, 45 .

5. Jadhav, A.H.; Kim, H.; Hwang, I.T. Biores. Technol. 2013, 132, 342.

6. Huang, H.; Denard, C.A.; Alamillo, R.; Crisci, A.J.; Miao, Y.R.; Dumesic, J.A.; Scott, S.L.; Zhao, H.M. ACS Catalysis 2014, 4, 2165.

7. Antal, M. J.; Mok, W. S. L.; Richards, G. N. Carbohyd. Res. 1990, 199, 91.

8. Zhao, H. B.; Holladay, J. E.; Brown, H.; Zhang, Z. C. Science 2007, 316,1597.

9. Heravi, M. M.; Ansari, P.; Saeedi, M.; Karimi, N.; Tavakoli-Hosseini, N. Bull. Chem. Soc. Ethiop. 2011, 25, 315.

10. Liu, S.W.; Wang, Z.P.; Yu, S.T.; Xie, C.X. Bull. Chem. Soc. Ethiop. 2013, 27, 289.

11. Kondamudi, K.; Elavarasan, P.; Dyson, P.J. J. Mol. Catal. A: Chem. 2010, 321, 34.

12. Steinkoenig, J.; Bloesser, F.R.; Huber, B.; Welle, A.; Trouillet, V.; Weidner, S.M.; Barner, L.; Roesky, P.W.; Yuan, J.Y.; Goldmann, A.S.; Barner-Kowollik, C. Polym. Chem. 2016, 7, 451.

13. Lapidus, A.L.; Eliseev, O.L. Solid Fuel Chem. 2010, 44, 197.

14. Lansalot-Matras, C.; Moreau, C. Catal. Commun. 2003, 4, 517.

15. Moreau, C.; Finiels, A.; Vanoye, L. J. Mol. Catal. A: Chem. 2006, 253, 165.

16. Liu, S.W.; Xie, C.X.; Yu, S.T.; Liu, F.S. Catal. Commun. 2008, 9, 2030.

17. Liu, S.W.; Zhou, H.X.; Yu, S.T.; Xie, C.X.; Liu, F.S.; Song, Z.Q. Chem. Eng. J. 2011, 174, 396.

18. Coffie, S.; Hogg, J.M.; Cailler, L.; Ferrer-Ugalde, A.; Murphy, R.W.; Holbrey, J.D.; Coleman, F.; Swadźba-Kwaśny, M. Angew. Chem. Int. Ed. 2015, 54, 149703.

19. Wasserscheid, P.; Keim, W. Angew. Chem. Int. Ed. 2000, 39, 3772.

20. Xing, H.; Wang, T.; Zhou, Z.; Dai, Y. J. Mol. Catal. A: Chem. 2007, 264, 53. 